\title{
Recovering the Demographical History of a Brazilian Cerrado Tree Species Caryocar brasiliense: Coupling Ecological Niche Modeling and Coalescent Analyses
}

\author{
Rosane Garcia Collevatti ${ }^{1 *}$, Matheus Souza Lima-Ribeiro², Advaldo Carlos Souza-Neto, \\ Amanda Assis Franco ${ }^{2}$, Guilherme de Oliveira ${ }^{2}$ \& Levi Carina Terribile ${ }^{2}$
}

\author{
${ }^{1}$ Laboratório de Genética \& Biodiversidade, Instituto de Ciências Biológicas, Universidade Federal de Goiás - UFG, \\ Goiânia, GO, Brasil \\ ${ }^{2}$ Laboratório de Macroecologia, Universidade Federal de Goiás - UFG, Jataí, GO, Brasil
}

\begin{abstract}
Here we studied the demographical history of Caryocar brasiliense (Caryocaraceae), by coupling ecological niche modeling (ENM) and statistical phylogeography. Analyses were based on the polymorphism of 147 individuals sampled in 12 populations for the chloroplast genome. C. brasiliense presented low genetic diversity but high population genetic differentiation, which is not correlated with geographical distances among localities. The most ancient lineage divergence from southern and western Cerrado boundaries occurred around $\sim 3.3 \pm 2.3 \mathrm{Myr}$ BP. The simulation of demographic scenarios showed that the diversity pattern found so far for $C$. brasiliense is most likely due to a range retraction during the last glacial maximum (LGM, 21 kyr BP), leading to multiple refugia. The paleodistribution models and coalescent analyses strongly suggest that the current distribution of $C$. brasiliense is wider than during the dry periods of the Quaternary.
\end{abstract}

Key words: Caryocaraceae, Coalescence, Palaeodistribution Modeling, Quaternary Climate Changes, Neotropical Savanna.

\section{Introduction}

Recovering the demographic history in phylogeography is critical for understanding the microevolutionary processes and the spatial context of the time and pattern of lineages divergences (Knowles \& Maddison 2002). Phylogeography has been discussing this question mainly in pattern-based models (see Avise 2009 for a review), but recovering the demographical history essentially requires the simulation of competing demographic models to estimate genetic parameters (e.g. Peter et al. 2010; Collevatti et al. 2012a). This new approach has been named statistical phylogeography (Knowles \& Maddison 2002) and one of its main challenge is to define biologically sounding demographical scenarios that could be modeled using coalescent simulations (e.g., Carstens \& Knowles 2010).

In this context, ecological niche modeling (ENM) may reveal novel distribution patterns and suggest alternative past demographic hypotheses, which are spatially explicit and intrinsically independent from hypotheses built upon phylogenetic and coalescence modeling (e.g. Richards et al.

\footnotetext{
*Send correspondence to: Rosane Garcia Collevatti Laboratório de Genética \& Biodiversidade, Instituto de Ciências Biológicas, Universidade Federal de Goiás - UFG, CP 131, CEP 74001-970, Goiânia, GO, Brasil

E-mail: rosanegc68@hotmail.com
}

2007). This approach may be useful to test hypotheses about the role of Quaternary climate changes on vegetation dynamics in the Neotropics (e.g. Carnaval \& Moritiz 2008; Collevatti et al. 2012a) and, hence, on their phylogeographical patterns, as addressed here for Caryocar brasiliense Cambess. (Caryocaraceae).

Caryocar brasiliense is a Neotropical savanna tree species widely distributed in Brazilian Cerrado from Tocantins in the central-northern Brazil, towards the southwestern and southeastern Brazil (see Figure S1). Because of its wide distribution, C. brasiliense is suitable good biological model for testing hypotheses concerning the evolution of Neotropical savannas. Based on the phylogeographical pattern, Collevatti et al. (2003) hypothesized that multiple lineages may have contributed to the origin of $C$. brasiliense populations in Brazilian Cerrado and that the lineages became restricted to refugia where moist climatic conditions remained during the periods of dry and colder climate through the last ice age. Yet, those populations may have spread and dispersed to suitable areas latter than 7,000 years ago, attaining the current geographical range. Recently, it has been suggested that Brazilian savannas dated from the Late Miocene (<10 Myr BP) and had diversified due to an in situ evolution of adaptation to fire (Simon et al. 
2009). Simon et al. (2009) suggest that the very recent evolution of savanna lineages may have been caused by an expansion during the dry glacial periods. In fact, an expansion of Brazilian savannas towards the Amazon region accompanied by a retraction of the rainforests during dry glacial periods has already been suggested (e.g. Veloso 1963). However, Ab'Saber (2000) points out a retraction of savanna-like vegetation during the glacial periods and, mostly important, a highly heterogeneous response of the vegetation community. The fossil records also show a mosaic in the response of savanna vegetation to the Quaternary climatic changes, with an expansion of open grassy savanna during dry glacial, especially in the south and central distribution of Cerrado biome (e.g. Salgado-Labouriau et al. 1997).

Hence, it is possible to raise alternative hypotheses for savanna paleodistribution and establish competing demographic scenarios for a species' range dynamics and for the role of the Quaternary climate changes in its current pattern of genetic diversity and geographical distribution. Paleoscenario hypothesis of range dynamics, such as expansion, retraction or stability, through the Quaternary may well be tested using ENMs, and these in turn would lead to different patterns of genetic diversity, genetic differentiation among populations and coalescence patterns (Arenas et al. 2012, see also Additional Supporting Information for details about Brazilian Cerrado and our predictions). Thus, here we coupled coalescence analyses and ENMs to trace the demographical history of $C$. brasiliense and test its response to climatic changes during the Quaternary.

\section{Material and Methods}

\section{Genetic data}

A detailed description of genetic data used to characterize populations of $C$. brasiliense is given elsewhere (Collevatti et al. 2003). Four other populations were added to the original database of Collevatti et al. (2003), as well as samples from the outgroups (see Table S1 in the Additional Supporting Information, available at www.abeco.org.br). Distance between pairs of populations ranged from $\sim 200 \mathrm{~km}$ to approximately $1,300 \mathrm{~km}$ (Figure S1a in the Additional Supporting Information). In short, sequence data from two intergenic spacers ( $p s b A$-trnH and trnC-ycf6) of chloroplast DNA (cpDNA) were obtained, and concatenated to the data of the intron trnL from Collevatti et al. (2003).

\section{Genetic diversity and phylogeographical patterns}

Genetic parameters were estimated for each population and for polled data from all populations to obtain the total amount of polymorphism and genetic diversity currently found in $C$. brasiliense. Nucleotide $(\pi)$ and haplotype $(h)$ diversity were estimated using ArlequinVer 3.11 (Excoffier et al.
2005). Intraspecific phylogeny was inferred using medianjoining network analysis implemented in Network 4.6.1.0 (Forster et al. 2004). Population genetic differentiation statistic $\left(F_{S T}\right)$ was obtained from an analysis of molecular variance (AMOVA) and linearized pairwise $F_{S T}$ was correlated with the geographical distance matrix (logarithm) between pairs of populations by a Mantel test, using ArlequinVer 3.11 (Excoffier et al. 2005). The hypothesis that the current pattern of haplotype diversity and distribution was caused by a bottleneck followed by a sudden expansion, for each population and overall population was tested using the Raggeness Index R and Fu' F neutrality test implemented in ArlequinVer 3.11 (Excoffier et al. 2005).

Coalescent model (Kingman 1982) was used to estimate demographic parameters. For details on coalescence analyses see Collevatti et al. (2012a). The demographic parameters $\theta$ (mutation parameter), $g$ (exponential growth rate) and $\mathrm{M}$ (immigration rate) were estimated based on a Bayesian estimation using Markov Chain Monte Carlo (MCMC) approach implemented in LAMARC 2.1.8 (Kuhner 2006). We used the evolutionary model TIM $2+\mathrm{G}(-\ln \mathrm{L}=1401.8660)$, with gama shape equal to 0.0140 . The effective population size was estimated from the mutation parameter. Time to most recent common ancestor (TMRCA) was estimated based on Bayesian phylogenetic analysis implemented in BEAST 1.7.4 (Drummond \& Rambaut 2007), and mutation rates previously estimated for chloroplast non-coding regions were used to get time in years (Yamane et al. 2006). We also constrained the basal node to be no older than 55.5 Myr, in the Early Eocene, which corresponds to the earliest known occurrence of the genus Caryocar on the pollen fossil record from Venezuela (Rull 2000).

\section{Paleodistribution modeling and demographical history}

We modeled species distribution for present, mid-Holocene (6 kyr BP) and LGM (21 kyr BP) using the ensemble approach from 10 ENM methods and five coupled AtmosphereOcean General Circulation Models (AOGCMs), so that 50 predictive maps were obtained for each time period. All ENM methods are implemented in the computational platform BIOENSEMBLES (Diniz-Filho et al. 2009). Technical details about occurrence records and climate layers development used to build the ENMs can be obtained in Terribile et al. (2012) (see also Figure S1b and Tables S2-S5 in Additional Supporting Information for more details).

The 50 predictive maps were firstly visually inspected and then classified using range shift (difference in predicted range size) between current and LGM geographical ranges. The supported hypotheses were: i) "Range Stability", no difference in range size; ii) "Range Retraction", range size was lower in the LGM than in the present-day; and iii) "Range Expansion", range size was higher in the LGM than in the present-day. The relationship between the 
maps classification and the sources of variation (i.e. ENM methods, AOGCMs and interaction) was analyzed by a log-linear analysis. The range retraction would lead to high genetic differentiation among populations, and the subsequent spatial expansion in the interglacial periods may also induce the structuring of newly colonized areas into distinct sectors of low genetic diversity, with high frequency of an allele or a new mutation due to allele surfing and a gradient in genetic diversity (Excoffier et al. 2009). Therefore we analyzed the relationships among genetic diversity vs. climatic stability and distance from the centroid of the geographical range predicted by "Range Retraction" maps using quantile regressions (Cade \& Noon 2003).

Afterwards, the demographical history of C. brasiliense was modeled and simulated following the framework described in Collevatti et al. (2012b). Four independent demographic scenarios were modeled (Figure 1), derived from the hypothesis supported by ENM, 'Range Stability', 'Range Expansion', 'Range Retraction', or from a priori biogeographical hypothesis, 'Multiple Refugia', following Ab'Saber (2000), Collevatti et al. (2003) and evidences from the pollen fossil record (see Supporting Information). Demographic scenarios were simulated (2,000 independent simulations) based on coalescent analysis implemented in the software ByeSSC (Excoffier et al. 2000), using as priors the mutation rate and evolutionary model obtained for $C$. brasiliense cpDNA (see Figure 1 for details). The number of generations until the LGM (21 kyr BP) was calculated using a generation time of 15 years (RG Collevatti unpublished data).

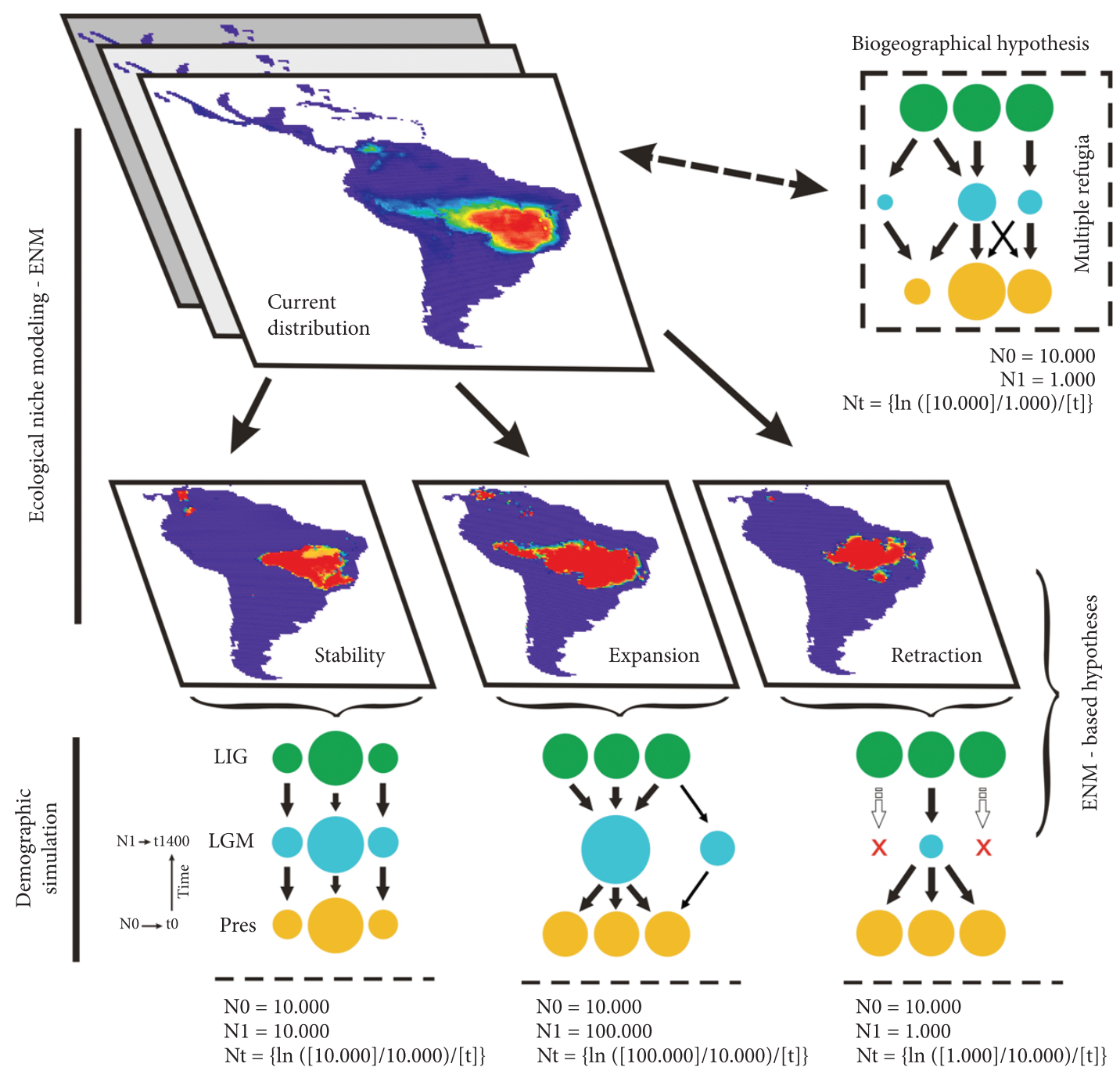

Figure 1. The demographical history scenarios simulated for Caryocar brasiliense and their geographical representation. The size and location of circle during the LGM indicate demographical population stability, expansion or shrink at that time. LIG: last interglacial; LGM: last glacial maximum; Pres: present-day; N0: effective population size at time t0 (present); N1: effective population size at time t1400 (1,400 generations ago); Nt: logarithm function for effective population size variation in the coalescent simulation. The migration rate was 0.01 /generation. 
The alternative models were compared based on the empirical genetic diversity and the frequency distribution of haplotype and nucleotide diversity across the 2,000 simulations. Because C. brasiliense presented low genetic diversity (see results below), our question was which demographic scenario most likely retrieved a genetic diversity as low as that found in C. brasiliense. One-tailed probability $(P)$ and Akaike Information Criterion (AIC) were estimated for each demographic scenario model. The log-likelihood was estimated as the product of the height of the empirical frequency distribution at the observed value of diversity by the maximum height of the distribution (see BayeSSC website www.stanford.edu/group/hadlylab/ssc/index. html). AIC was transformed into AIC weighting, given by $\exp [-0.5$ (AIC - AICmin)] (see Burnham \& Andersson 2002).

\section{Results}

\section{Genetic diversity and phylogeographical} patterns

The combined data presented $981 \mathrm{bp}, 17$ polymorphic sites and 8 different haplotypes for the 147 individuals of C. brasiliense. Most populations presented low genetic diversity (Table S6 in the Additional Supporting Information), and only one haplotype was shared among most populations (Figure 2), with evidences of incomplete lineage sorting leading to common ancestry among lineages from southeastern and northeastern (see Haplotypes 6, 7, 8, Figure 2, Figure S2). Significant pairwise differentiation was found, but it was not significantly correlated with geographical distance (Mantel Test, $\mathrm{r}^{2}=0.004, P=0.353$ ).

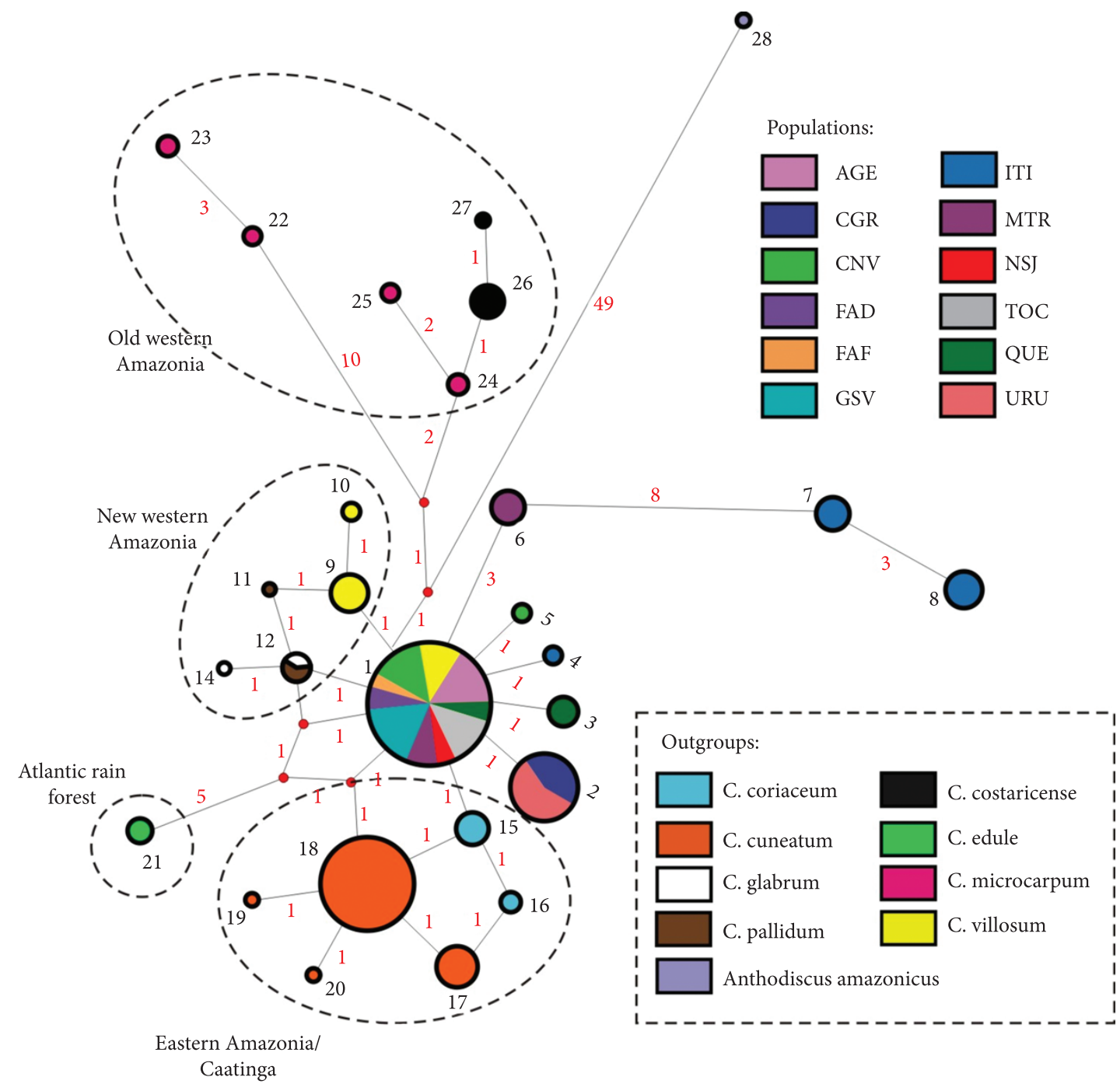

Figure 2. Median-joining network based on the sequencing of 147 individuals of Caryocar brasiliense from 12 populations and the outgroups. Circumference size is proportional to the haplotype frequency. Number of mutations are shown in the branches; small red circles are the median vectors. Old western Amazonia refers to the clade that diverged during the Late Paleoceno/Early Eocene; New western Amazonia, the clade that diverged during the Pleistocene (see Figure S2 in the Additional Supporting Information). 
No significant signal of population retraction followed by expansion was found when pooling populations according to Roger-Harpending test (Raggedness index $=0.10, P=0.52$ ), but Fu's test was significant (FS $=-26.42, P<0.001$ ), indicating departure from neutrality. Demographic expansion was significant for MTR (Raggedness index $=0.787$, $P=0.025 ; \mathrm{FS}=-24.905, P<0.001$ ) and QUE (Raggedness index $=0.510, P=0.028 ; \mathrm{FS}=-15.521, P<0.001)$. Coalescent analyses also showed constant population size, low values of mutation parameter $\theta$ for each and overall population $(\theta=0.00225)$, and negligible gene flow (less than 1.0 migrant per generation among all population pairs). Caryocar brasiliense lineages diverged at $\sim 4.0 \pm 2.5 \mathrm{Myr}$ BP and major divergence dated from the Pliocene/Lower Pleistocene, $\sim 3.3 \pm 2.3$ Myr BP (see Tables S5, S6 and Figure S2 in the Additional Supporting Information, for details).

\section{Paleodistribution modeling and demographical history}

The ensembled potential distribution of $C$. brasiliense extends over a widely continuous area through the Central-West Brazil since LGM (Figure 3a), matching the Brazilian Cerrado limits, with higher variation in the peripheral areas (Figure $3 \mathrm{~b}$ ). However, a slight westward migration occurred through time with smaller range size at the LGM. Further, the scenario of "Range Retraction" during the LGM was favored in the most predictive maps (42\%; Table S7 in the Additional Supporting Information). These predictions show still that range retraction was followed by range shift toward Amazonian rain forest, regions not currently occupied by C. brasiliense. The range size and shift differ among supported hypotheses (Range size: $\mathrm{F}_{2,47}=6.27$, $P=0.004$; Range shift: $\mathrm{F}_{2,47}=66.71, P<0.001$; Figure S3) and the log-linear analysis showed significant effects of AOGCMs in the classification of the predictive maps (Table S8 in the Additional Supporting Information), but not from ENM methods and interaction. A large historical refugium of C. brasiliense (areas of high climatic suitability throughout time) was predicted from ENMs to occur in central-northern and northwestern portions of its current geographical range, where most populations occur in present-day (Figure 3c). Moreover, the quantile regression revealed triangular-shaped envelopes for relationships among genetic diversity vs. climatic stability and distance from the centroid of predictive maps at the LGM. The envelopes show thus that high genetic diversity occurs just in the peripheral populations (distant from centroid; e.g., ITI and MTR) with increase in suitability throughout time, but not in all them (i.e., instable areas; Figure S4 in the Additional Supporting Information).

The demographical hypothesis of 'Multiple Refugia' during the LGM (Figure 1) was most likely than the others competing hypotheses (Table 1), even though the "Range Retraction" hypothesis, predicted by the paleodistribution models (Figure 1), could not be rejected. The simulations of the demographic scenarios "Range Expansion" and "Range Stability" retrieved diversity extremely higher than currently observed in C. brasiliense.

\section{Discussion}

Our ENM results show that the potential distribution of C. brasiliense is currently wider than it was in the LGM. Moreover, the pattern of genetic diversity is consistent with a demographic scenario of "Multiple Refugia" during glacial times, which also predicts a range retraction with population subdivision. Thus, the low haplotype and nucleotide diversity of $C$. brasiliense in present-day indicate a loss of chloroplast lineages due to range retraction during LGM. An important issue is that predictive maps classified as "Range Retraction" often showed also a range shift towards the Northwest Brazil, in areas currently occupied by Amazonian rain forest.

In fact, sampled populations of C. brasiliense at the centralnorthern and northwestern Brazil occupy climatically stable areas (the large refugium), but show low genetic diversity in current time. These populations also share the same haplotype and present no significant differentiation, except QUE and MTR, which are western peripheral populations (see below). Our findings show thus a complex demographic history for C. brasiliense (corroborated by the "Multiple Refugia" scenario) in which populations could have been connected during the dry periods of the Quaternary in a large northwestern refugium, as also proposed from fossil records (see Ab'Saber 2000). The complex relationships of genetic diversity and geographical distance and with climate stability and distance from centroid are also evidences of the intricate demographic history and reinforce the multiple refugia hypothesis. The high diversity in a few peripheral populations (triangular-shaped envelopes) may have risen due to isolation in small and multiple refugia during the glacial periods of Quaternary, along with low gene flow during interglacial time, causing yet no haplotype sharing (the ITI population may be a relict of this distributional and demographical dynamic; see text below). The connected

Table 1. Comparison of the four demographic scenarios models in retrieve the haplotype (h) and nucleotide $(\pi)$ diversity observed for Caryocar brasiliense, obtained from 2,000 simulations using the software BayeSSC. AICw, relative Akaike Information Criterion (AIC) weights; $P$, one-tailed probability of not reject the model. The support to the distribution hypothesis (ENM) is the percentage of the pattern expected by each demographic scenario model observed in the 50 paleodistribution maps. See Figure 1 for details about the demographic scenarios. $h$ - haplotype diversity; $\pi$ - nucleotide diversity.

\begin{tabular}{|c|c|c|c|c|c|}
\hline \multirow{2}{*}{ Models } & \multicolumn{2}{|c|}{ AICw } & \multicolumn{2}{|c|}{$\mathbf{P}$} & \multirow{2}{*}{$\begin{array}{c}\text { ENM } \\
\%\end{array}$} \\
\hline & $h$ & $\pi$ & $h$ & $\pi$ & \\
\hline Stability & 0.031 & 0.015 & 0.072 & 0.396 & 28 \\
\hline Expansion & 0.005 & 0.079 & 0.004 & 0.753 & 30 \\
\hline Retraction & 0.327 & 0.293 & 0.949 & 0.999 & 42 \\
\hline Multiple refugia & 0.637 & 0.613 & 0.994 & 0.998 & - \\
\hline
\end{tabular}




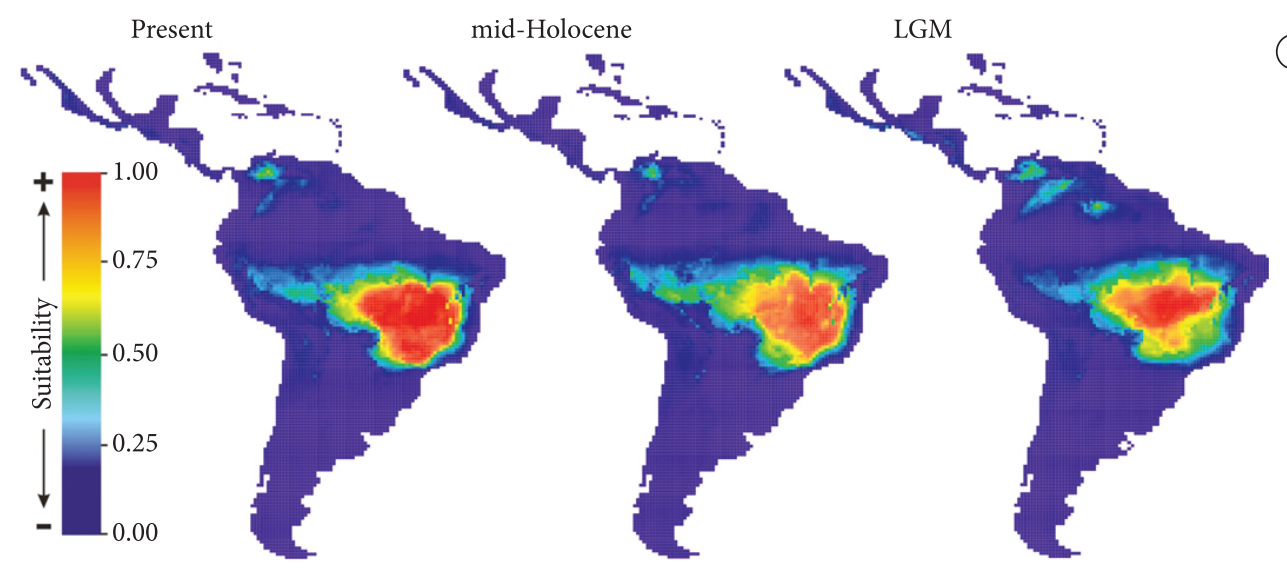

(a)

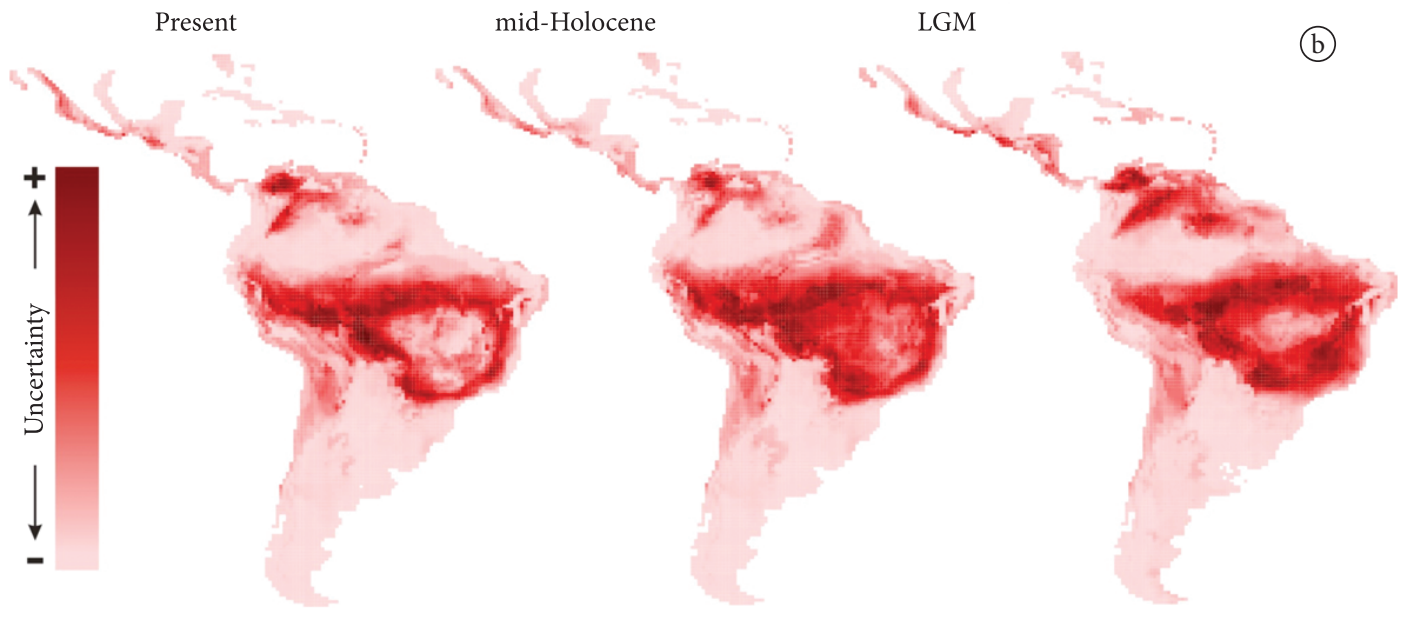

(c)

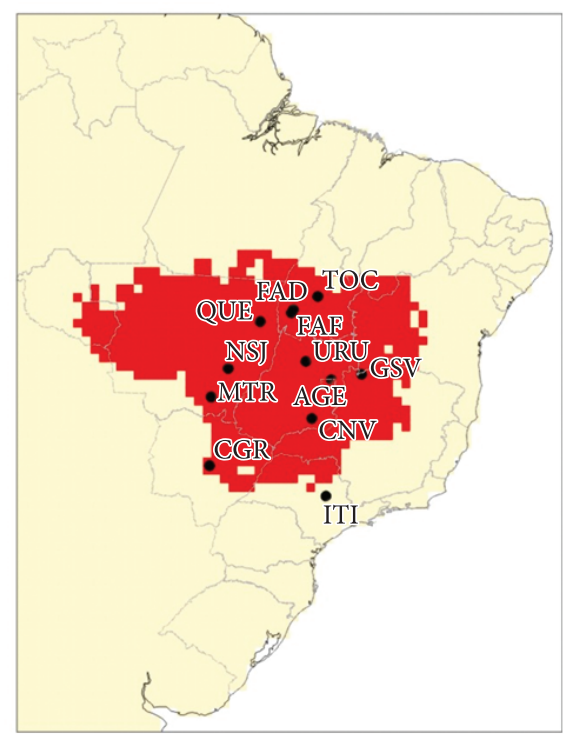

Figure 3. Maps of mean climatic suitability (a) and standard deviation of predictions (b) across the 10 ENMs, 5 AOGCMs used for paleodistribution modeling, and (c) map of historical refugium (climatic suitability $>0.5$ at the LGM, mid-Holocene and present) for Caryocar brasiliense. 
populations occupying the large historical refugium (i.e., stable areas near to the centroid of LGM range), in opposition, showed no pairwise differentiation, low genetic diversity and the sharing of a single frequent haplotype. This may also explain the evidences of incomplete lineage sorting, linking populations from the Southeast (ITI) and Northwest (MTR).

In addition, due to the highly discontinuous distribution of savanna during the dry periods of the Quaternary (Ab'Saber 2000), the colonization in different sectors could also have favored the high frequency of a haplotype due to allele surf (Arenas et al. 2012). This haplotype could thus have been shared among the northern populations during the spatial expansion through the interglacial periods. However, C. brasiliense shows high genetic diversity for these populations at nuclear microsatellite loci (see Collevatti et al. 2001). Despite differences in mutation rates and pollen and seed dispersal (Collevatti et al. 2003), the low diversity in chloroplast genome compared to nuclear ones suggests selective sweep in chloroplast genome, as reported for other plant species (e.g. Kapralov \& Filatov 2007). Indeed, Fu's neutrality test was significant for overall populations and for two polymorphic populations (MTR and QUE), western peripheral populations, indicating a positive selection.

Notwithstanding, despite the high climatic instability through the last glacial cycle indicated by the ENMs, our results indicated that the inner São Paulo plateaus in the southeastern Brazil could have been a savanna-like refugium (probably small refugium, corroborating the "Multiple Refugia" scenario). The sampled population from this region (ITI) presented the highest genetic diversity and the deepest lineages divergence $(\sim 3.3 \pm 2.3 \mathrm{Myr} \mathrm{BP}$, see Figure S2). Ab'Saber (2000) pointed out that this region was a stable area of savanna-like vegetation during the dry periods of the Quaternary and we cannot exclude it as savanna-like refugium based on paleodistribution models because of the coarse spatial resolution $\left(0.5^{\circ} \times\right.$ $0.5^{\circ}$ latitude/longitude) from climatic layers used to build the ENMs. The vegetation dynamic at fine spatial scales, whose signal is not captured by coarse ENMs, may have caused multiple small refugia of savanna-like vegetation and hence the ancient divergence from the southeastern lineages of $C$. brasiliense along with highest genetic diversity. In addition, phylogeographical patterns as complex as this reveled for C. brasiliense is also shown for other tree species from Brazilian Cerrado, although not exactly from multiple refugia scenario (Novaes et al. 2010; Collevatti et al. 2009, 2012c).

In conclusion, our results show a substantial effect of climate changes on demographical history and lineage divergence of C. brasiliense and strongly support a scenario of "Multiple Refugia" as a result of the retraction of its geographical range during the LGM. Our study also corroborates the evidence for recent diversification of Brazilian savanna lineages, dated from 4.0 Myr BP or later, overlapping the time of divergence of C. brasiliense lineages. Furthermore, the present study reinforces the idea that phylogeographical analyses coupling ecological niche modeling and coalescent simulations provide a more powerful framework for evaluating alternative hypotheses and to disentangle the mechanisms involved in the species evolutionary history.

\section{Acknowledgements}

This work was supported by a PRONEX CNPq/FAPEG/ AUX PESQ CH 007/2009. Our research program integrating macroecology and molecular ecology has been continuously supported by grants to the research network GENPAC (Geographical Genetics and Regional Planning for natural resources in Brazilian Cerrado) supported by CNPq/MCT/ CAPES (projects no. 564717/2010-0, 563727/2010-1 and $563624 / 2010-8$ ), which we gratefully acknowledge. We thank Thiago F. Rangel for providing access to computational platform BIOENSEMBLES, which was essential to our ecological niche modeling analyses. We also acknowledge the World Climate Research Programmer's Working Group on Coupled Modeling, which is responsible for CMIP5, and we thank the climate modeling groups (listed in Additional Supporting Information Table S3 of this paper) for producing and making available their model outputs.

\section{References}

Ab'Saber AN, 2000. Spaces Occupied by the Expansion of Dry Climates in South America During the Quaternary Ice Ages. Revista do Instituto Geológico, 21:71-78.

Arenas $\mathrm{M}$ et al., 2012. Consequences of range contractions and range shifts on molecular diversity. Molecular Biology and Evolution, 29:207-218. PMid:21778191. http://dx.doi. org/10.1093/molbev/msr187

Avise JC, 2009. Phylogeography: retrospect and prospect. Journal of Biogeography, 36:3-15. http://dx.doi. org/10.1111/j.1365-2699.2008.02032.x

Burnham KP \& Anderson DR, 2002. Model selection and multimodel inference: a practical information-theoretic approach. 2nd ed. New York: Springer.

Cade BS \& Noon BR, 2003. A gentle introduction to quantile regression for ecologists. Frontiers in Ecology and the Environment, 1:412-420. http://dx.doi. org/10.1890/1540-9295(2003)001[0412:AGITQR]2.0.CO;2

Carnaval AC \& Moritz C, 2008. Historical climate modelling predicts patterns of current biodiversity in the Brazilian Atlantic forest. Journal of Biogeography, 35:1187-1201. http:// dx.doi.org/10.1111/j.1365-2699.2007.01870.x

Carstens BC \& Knowles LL, 2010. Navigating the unknown: model selection in phylogeography. Models of population structure: tools for thinkers. Molecular Ecology, 19:4581-4582. PMid:20958809. http://dx.doi. org/10.1111/j.1365-294X.2010.04851.x

Collevatti RG, Grattapaglia D \& Hay JD, 2001. Population genetic structure of the endangered tropical tree species Caryocar brasiliense, based on variability at microsatellite loci. Molecular Ecology, 10:349-356. PMid:11298950. http:// dx.doi.org/10.1046/j.1365-294x.2001.01226.x 
Collevatti RG, Grattapaglia D \& Hay JD, 2003. Evidences for multiple maternal lineages of Caryocar brasiliense populations in the Brazilian Cerrado based on the analysis of chloroplast DNA sequences and microsatellite haplotype variation. Molecular Ecology, 12:105-115. PMid:12492881. http://dx.doi.org/10.1046/j.1365-294X.2003.01701.x

Collevatti RG, Rabelo SG \& Vieira RF, 2009. Phylogeography and disjunct distribution in Lychnophora ericoides (Asteraceae), an endangered cerrado shrub species. Annals of Botany, 104:655-664. PMid:19656805 PMCid:2729634. http://dx.doi.org/10.1093/aob/mcp157

Collevatti RG et al., 2012a. A coupled phylogeographical and species distribution modelling approach recovers the demographical history of a Neotropical seasonally dry forest tree species. Molecular Ecology, 21: 5845-5863. PMid:23094833. http://dx.doi.org/10.1111/mec.12071

Collevatti RG et al. 2012b. Drawbacks to palaeodistribution modelling: the case of South American seasonally dry forests. Journal of Biogeography. In press.

Collevatti RG et al., 2012c. Phylogeography of Tibouchina papyrus (Pohl) Toledo (Melastomataceae), an endangered tree species from rocky savannas, suggests bidirectional expansion due to climate cooling in the Pleistocene. Ecology and Evolution, 2(5):1024-1035. http://dx.doi.org/10.1002/ ece 3.236

Diniz-Filho JAF et al. 2009. Partitioning and mapping uncertainties in ensembles of forecasts of species turnover under climate change. Ecography, 32:897-906. http://dx.doi. org/10.1111/j.1600-0587.2009.06196.x

Drummond AJ \& Rambaut A, 2007. BEAST: Bayesian Evolutionary Analysis by Sampling Trees. BMC Evolutionary Biology, 7:214. PMid:17996036 PMCid:2247476. http:// dx.doi.org/10.1186/1471-2148-7-214

Excoffier L, Novembre J \& Schneider S, 2000. SIMCOAL: a general coalescent program for simulation of molecular data in interconnected populations with arbitrary demography. Journal of Heredity, 91:506-509. PMid:11218093. http:// dx.doi.org/10.1093/jhered/91.6.506

Excoffier L, Laval G \& Schneider S, 2005. Arlequin ver. 3.0: An integrated software package for population genetics data analysis. Evolutionary Bioinformatics Online, 1:47-50.

Forster P, Bandelt HJ \& Röhl A, 2004. Network 4.2.0.1. Fluxus Technology Ltda. Software free. Available from: <www. fluxus-engineering.com $>$.

Kapralov MV \& Filatov DA, 2007. Widespread positive selection in the photosynthetic Rubisco enzyme. BMC Evolutionary Biology, 7:73. PMid:17498284 PMCid:1884142. http:// dx.doi.org/10.1186/1471-2148-7-73
Kingman JFC, 1982. The coalescent. Stochastic Processes and their applications,13:235-248. http://dx.doi. org/10.1016/0304-4149(82)90011-4

Knowles LL \& Maddison WP, 2002. Statisical phylogeography. Molecular Ecology, 11:2623-2635. PMid:12453245. http:// dx.doi.org/10.1046/j.1365-294X.2002.01637.x

Kuhner MK, 2006. LAMARC 2.0: maximum likelihood and Bayesian estimation of population parameters. Bioinformatics, 22:768-770. PMid:16410317. http://dx.doi. org/10.1093/bioinformatics/btk051

Novaes RM et al., 2010. Phylogeography of Plathymenia reticulate (Leguminosae) reveals patterns of recent range expansion towards northeastern Brazil and southern Cerrados in Eastern Tropical South America. Molecular Ecology, 19:985-998. PMid:20149092. http://dx.doi. org/10.1111/j.1365-294X.2010.04530.x

Peter BM, Wegman D \& Excoffier L, 2010. Distinguishing between population bottleneck and population subdivision by a Bayesian model choice procedure. Molecular Ecology, 19:4648-4660. PMid:20735743. http://dx.doi. org/10.1111/j.1365-294X.2010.04783.x

Richards CL, Carstens BC \& Knowles LL, 2007. Distribution modeling and statistical phylogeography: an integrative framework for testing biogeographic hypotheses. Journal of Biogeography, 34:1833-1845. http://dx.doi. org/10.1111/j.1365-2699.2007.01814.x

Rull V, 2000. Ecostratigraphic study of Paleocene and Early Eocene palynological cyclicity in northern South America. Palaios, 15:14-24.

Salgado-Labouriau ML, 1997. Late Quaternary paleoclimate in the savannas of South America. Journal of Quaternary Science, 12:371-379. http://dx.doi.org/10.1002/(SICI)10991417(199709/10)12:5<371::AID-JQS320>3.0.CO;2-3

Simon MF et al., 2009. Recent assembly of the Cerrado, a neotropical plant diversity hotspot, by in situ evolution of adaptations to fire. Proceedings of the National Academy of Sciences of the United States of America, 106:20359-20364. PMid:19918050 PMCid:2787167. http://dx.doi.org/10.1073/ pnas.0903410106

Terribile LC et al., 2012. Areas of climate stability in the Brazilian Cerrado: disentangling uncertainties through time. Natureza \& Conservação, 10(2): 152-159. http:// dx.doi.org/10.4322/natcon.2012.025

Yamane K, Yano K \& Kawahara T, 2006. Pattern and rate of indel evolution inferred from whole chloroplast intergenic regions in sugarcane, maize and rice. DNA Research, 13:197-204. PMid:17110395. http://dx.doi.org/10.1093/dnares/ds1012 